TION, of which Dr. U. O. B. Wingate, Secretary of the Wisconsin State Board of Health, is chairman, is also engaged in the preparation of a bill for the establishment of a National Department of Public Health.

It remains for the American people to understand the case, take a lively interest therein, and help the action that shall be for the greatest good.

\section{GONORRHEAL OPHTHALMIA-REPORT OF A CASE TREATED WITH ARGONIN.}

BY FRANK TRESTER SMITH, A.M., M.D.

PROFESSOR OF DISEASES OF THE EYE, CHATTANOOGA MEDICAL COLLEGE. CHATTANOOGA, TEN.

C. D. R., male, aged 33 . First seen Nov. 25, 1896 Two weeks before, right eye became sore, for which he was treated by his family physician. It was extremely painful until two days before, when something seemed to give way and water gushed from between the lids, after which it became easier.

There was an abundant purulent discharge. The cornea was not clear at any point but had a fleshy appearance and bulged from the general curvature of the eyeball (total staphyloma).

The man lived at some distance in the country and failed to attend regularly, coming only once or twice a week. For two weeks he was treated in the usual way with boracic acid, bichlorid and nitrate of silver with very little effect on the discharge, which was abundant from the time first seen. A microscopic examination by Dr. E. C. Anderson, chief of the Microscopic Laboratory of the Chattanooga Medical College, showed the presence of gonococci in abundance. The patient had gonorrhea.

Thinking this a favorable case to test argonin, as the eye was hopelessly lost, a 5 per cent. solution was instilled into the eye. The application caused no pain and a solution was given the patient for use at home. Four days later he reported that the discharge had almost entirely ceased after the first use of the argonin. $\mathrm{He}$ had kept samples of the discharge, which were preserved on cotton swabs made by wrapping pledgets of cotton on toothpicks. These were sealed in envelopes as soon as obtained. An examination of these failed to show a single gonococcus. A sample of the discharge taken direct from the inside of the lid was found to contain a few, very few gonococci.

The argonin was continued. A few days later the eye again became very painful. The tension was increased to plus 1 and the staphyloma was larger. The ball was incised and the clear lens escaped. There was no pus inside the eye. There was no further pain and the patient ceased his visits owing to sickness in his family. One of his neighbors reported that he had no further trouble. The fellow eye was unaffected during the whole of the treatment.

This case seems to indicate that argonin can be used safely in the eye; that it is less irritating than nitrate of silver and from its wonderful effect on the discharge and the development of the gonococci it appears to be the ideal remedy in purulent ophthalmia. Further tests will demonstrate its true value.

ONLY A DROP OF WATER.

BY D. LICHTY, M.D. ROCKFORD, ILL.

Dr. Jacobi, after deploring the fatality following tracheotomies in diphtheria and membranous croup, says: "The results of any treatment in membranous croup are of so doubtful a character that any observation both faithfully made and reported may be of service."

This passage, italicized by myself, will be the apology for offering and having recorded a single successful item in the after-treatment of croup with tracheotomy.

Every one with experience in the after-treatment. and care of the tube in tracheotomy whether for croup or diphtheria, must be painfully conscious of the inefficiency of the methods thus far suggested and employed to maintain a sufficient degree of moisture in the tube to prevent the hardening and drying of the exudate and the sticking of the membranes in the dry metallic tube; sprays and vapors can not be generated in volume great enough, or be induced to enter the narrow aperture of the tube in sufficient quantity to even dampen its lumen a quarter of an inch from its distal extremity, while the dry air passing on at each inspiration impinges on the tracheal mucosa only to $a b s o r b$ the little remaining moisture the diseased conditions have created; the result is, a hard brown plug soon forms within and around the proximal end of the canula that neither swabs or hen's feathers can remove; and the distress of flap-valve respiration, or the hazard of occlusion and the prompt removal of the tube and its re-insertion confronts the anxious attendant; it is this difficulty more than any other that interferes with the successful local after-treatment of tracheotomies, and makes the postponement of this surgical procedure often too long deferred.

A recent experience in this line, when every mod. ern means of supplying moisture to the trachea through the tube was being employed, with the threatening failure that usually follows, it was suggested, by recalling the experiments along the line of Rossbach and Calvert in supplying moisture to the inner tracheal area by hypodermic means that "normal salt solution" might be safely supplied through the canula in quantities sufficient not only to moisten the interior of the tube, but to also diffuse over the mucous surface of the trachea and membranes; the experiment was so satisfactorily successful that the nurses, the patient, a little three-year old, and the attending physician were all wonderfully relieved of the further impending peril of occlusion of the tube, and progress, from the introduction of this feature, went on to complete and uneventful and uninterrupted recovery, the tube being removed on the eighth day.

The salt solution was warmed to the temperature of the blood and allowed to trickle down the canula by means of the ordinary medicine dropper, one, two or three drops, in slow succession until the to-and-fro respiratory râle indicated that there was moisture enough, and soon the patient would pass into calm repose; this would be repeated as often as the indications called for it, and instead of the violent paroxysms of dyspnea, with coughing and straining to expel a plug of dried and hardened mucus and membrane, the exudate poured out a stringy, purulent stream easily caught up by the nurses on pledgets of gauze, or wiped away with an easy whirl of the sterilized hen's feathers in the tube.

Did this normal salt solution mingling with the remaining tracheal mucus have a solvent or bactericidal effect on the pathologic membrane?

If this observation will reach those who have oppor- 